\title{
Preparedness or repeated short-term relief aid? Building drought resilience through early warning in southern Africa
}

\author{
L Nhamo'*, T Mabhaudhi ${ }^{2}$ and AT Modi ${ }^{2}$ \\ 'International Water Management Institute (IWMI), Southern Africa, 141 Cresswell Street, Weavind Park, Silverton, 0184, Pretoria, South Africa \\ ${ }^{2}$ Centre for Transformative Agricultural and Food Systems, School of Agricultural, Earth and Environmental Sciences, \\ University of KwaZulu-Natal, Scottsville, 3209, Pietermaritzburg, South Africa
}

\begin{abstract}
Southern Africa is highly vulnerable to drought because of its dependence on climate-sensitive sectors of agriculture, hydroenergy and fisheries. Recurring droughts continue to impact rural livelihoods and degrade the environment. Drought severity in southern Africa is exacerbated by poor levels of preparedness and low adaptive capacity. Whilst weather extremes and hazards are inevitable, the preparedness to manage such hazards determines their impact and whether they become disasters. Southern Africa is often caught unprepared by drought as existing early warning systems lack the drought forecasting component, which often results in reactionary interventions as opposed to well-planned and proactive response mechanisms. This study assesses the spatio-temporal changes of rainfall and aridity in southern Africa through an analysis of long-term precipitation and evaporation trends from 1960 to 2007. Stakeholder consultation was conducted in Madagascar, Malawi, Zambia and Zimbabwe during the peak of the 2015/16 drought, focusing on overall drought impacts, current water resource availability, existing early warning systems, adaptation mechanisms and institutional capacity to mitigate and manage droughts as part of overall disaster risk reduction strategies. Average rainfall has decreased by $26 \%$ in the region between 1960 and 2007, and aridity has increased by $11 \%$ between 1980 and 2007. The absence of drought forecasting and lack of institutional capacity to mitigate drought impede regional drought risk reduction initiatives. Existing multi-hazard early warning systems in the region focus on flooding and drought monitoring and assessment. Drought forecasting is often not given due consideration, yet it is a key component of early warning and resilience building. We propose a regional drought early warning framework, emphasising the importance of both monitoring and forecasting as being integral to a drought early warning system and building resilience to drought.
\end{abstract}

Keywords: drought, SADC, early warning system, water scarcity, resilience, disaster risk reduction

\section{INTRODUCTION}

Drought occurrence is intensifying both in frequency and severity in southern Africa, inflicting serious economic and social losses and worsening the vulnerabilities of the region (Tirado et al., 2015; Urama and Ozor, 2010). The complex and slow onset of drought, as well as its diverse origins and occurrence at different temporal and spatial scales, and widespread nature complicate its forecasting, monitoring and management (Hao et al., 2014). Apart from its complex nature, drought is one of the costliest natural disasters, often large in spatial extent and lengthy in duration, affecting whole regions and continents (Sheffield et al., 2014). However, there is significant progress globally in drought forecasting and monitoring, especially with the increased availability of satellite-based products (AghaKouchak et al., 2015; Hao et al., 2014). Nevertheless, as drought is generally widespread in nature, adaptation at regional level, as well as drought forecasting and management by respective national institutions, remains elusive owing to lack of institutional capacity and fragmented mandates. Three types of methods have been used to forecast drought: statistical, dynamical and hybrid methods (Mariotti et al. 2013; Pozzi et al., 2013). Statistical forecasting uses empirical relationships of historical records, taking different influencing factors as predictors. Dynamical forecasting refers to the use of general circulation

\footnotetext{
* To whom all correspondence should be addressed.
}

e-mail:1.nhamo@cgiar.org

Received 6 November 2017, accepted in revised form 10 December 2018. models (GCMs), which provide drought forecasting based on the physical processes of the atmosphere, ocean, and land surface. Hybrid methods combine both statistical and dynamical methods to forecast drought.

For three consecutive years (2014-16), the Southern African Development Community (SADC) region (a regional economic grouping of 15 southern Africa countries) was exposed to an intense drought, and during the 2015/16 rain season the situation was exacerbated by one of the strongest El Niño Southern Oscillation (ENSO) episodes on record (SADC, 2016). The 2015/16 drought became the worst to affect the region since the start of record keeping more than a century ago (FAO, 2016). In a region where more than $60 \%$ of rural livelihoods depend on agriculture (Tirado et al., 2015, Urama and Ozor, 2010), the impacts of the drought were quite severe as more than 40 million people became food insecure requiring international assistance (SADC, 2016). The severity of the 2015/16 drought resulted in 643000 livestock deaths due to lack of pasture and water (De Waal and Vogel, 2016). There was also an overall maize (the staple crop in the region) deficit of 5.1 million $\mathrm{t}$, which is a $10 \%$ decrease in production compared to the previous year and a $15 \%$ drop compared to the 5 -year average (Gizaw and Gan, 2016; SADC 2016). Its severity caused most regional countries to declare national emergencies. Consequently, the region had to declare a regional drought emergency and subsequently launched a 2.7 billion USD appeal to the international community to meet the food requirements of over 40 million people (SADC, 2016). Most countries in the region had to import maize, as local production was inadequate as there was an overall decline in production across the region (Table 1). The 2015/16 drought in the region highlights the 


\begin{tabular}{|c|c|c|c|c|c|}
\hline \multicolumn{6}{|c|}{$\begin{array}{l}\text { TABLE } 1 \\
2016 \text { maize production deficit in some SADC countries and the number of affected people }\end{array}$} \\
\hline Country & $\begin{array}{l}2011-2015 \text { average } \\
\text { ('000 tons) }\end{array}$ & $\begin{array}{l}2015 \text { maize } \\
\text { production ('000 tons) }\end{array}$ & $\begin{array}{l}2016 \text { maize } \\
\text { production ('000 tons) }\end{array}$ & $\begin{array}{l}\% \text { change } \\
2015 / 2016\end{array}$ & $\begin{array}{l}\text { No. of affected } \\
\text { people in } 2016\end{array}$ \\
\hline Angola & 1366 & 1878 & 1500 & -20 & 756000 \\
\hline Botswana & 21 & 4 & 1 & -75 & 1100000 \\
\hline Lesotho & 74 & 79 & 25 & -68 & 709000 \\
\hline Madagascar & 393 & 350 & 300 & -14 & 1400000 \\
\hline Malawi & 3583 & 2776 & 2369 & -15 & 6500000 \\
\hline Mozambique & 1602 & 1357 & 1350 & -1 & 2000000 \\
\hline South Africa & 12345 & 10629 & 7733 & -27 & 14300000 \\
\hline Swaziland & 89 & 82 & 33 & -60 & 638000 \\
\hline Zimbabwe & 1083 & 742 & 512 & -31 & 4000000 \\
\hline
\end{tabular}

Source: FAO GIEWS, $2016 b$

need for effective early warning systems with capacity to communicate accurate, appropriate and actionable information to increase levels of preparedness, especially given the added threat of recurring weather extremes under climate change.

Incidences of armyworm and locust invasion, which are associated with drought, were also reported in Madagascar, Malawi, South Africa, Zambia and Zimbabwe during the 2015/16 ENSO drought (Faithpraise et al., 2015; FAO 2016). The resultant low dam water levels caused by successive droughts triggered intermittent power outages in some regional countries that rely on hydro-electricity. With climate change projections for southern Africa indicating that the water sector is likely to face the greatest impacts (Schulze, 2012), drought impacts could only get worse in the near future. The impacts are already evident through low rainfall, increased rainfall variability and increased frequency and intensity of extreme weather events (Nhamo et al., 2018). These weather extremes are increasing the vulnerability of an already exposed population, as well as worsening water, food and energy insecurity.

The absence of a long-term comprehensive drought management strategy in southern Africa causes drought management efforts to rely on the delivery of relief aid post disaster rather than proactive resilience building (Lamboll et al., 2011; Osbahr 2007). As droughts and other climate change related disasters are increasing in frequency and intensity in the region, there is a need to build resilience through drought early warning. Drought early warning is the provision of timely and effective information, through identified institutions that allow individuals exposed to a drought hazard to act and reduce its impact and prepare for effective responses (Wilhite and Svoboda, 2000). Thus, failure to act will only worsen the plight of vulnerable populations and perpetuate poverty. The emphasis should be beyond short-term relief aid but towards transitioning vulnerable communities into resilient and sustainable communities. Achieving this requires a paradigm shift from the present reactionary approaches to one that is aimed at building and strengthening resilience; a key strategy would be breaking the cycle of food, water and energy insecurity that permeates in the region by increasing regional capacities linked to these strategic sectors through an integrated water-energy-food (WEF) nexus approach (Nhamo et al., 2018).

There are four types of drought (agricultural, meteorological, hydrological and socio-economic) and all are associated with a sustained period of precipitation deficit (Wilhite and Glantz, 1985; WMO and GWP, 2016). However, different elements of the hydrologic cycle respond to droughts differently and the four types of droughts are grouped according to their impact on the receiving environment (WMO and GWP, 2016). The four types of drought are (Wilhite and Glantz, 1985):

- Meteorological drought which is a prolonged period of dry weather (Wang et al., 2016; Wilhite and Glantz, 1985). It is characterised by increases in temperature, prolonged absence of rainfall and an accompanying decrease in humidity, which increases evapotranspiration (Basu et al., 2016).

- Agricultural drought which mainly affects the agricultural sector, wilting crops due to a prolonged period of moisture deficit (Wang et al., 1985; Wang et al., 2016). A decline in crop yields is associated with agricultural drought (Wang et al., 2016).

- Hydrological drought relates specifically to low hydro (water storage and flow) levels, causing deficiencies in water supply (Basu et al., 2016). It is a slow process drought that results when the supply of water from various water sources (lakes, streams and aquifers) drops below its normal level (Wilhite and Svoboda, 2000).

- Socio-economic drought is associated with economic losses and affects social aspects of life (Wilhite and Svoboda, 2000). It is characterised by an escalation in the demand for goods resulting in socio-economic impacts and famine or human starvation (Devereux, 2007; WMO and GWP 2016).

This study focuses on meteorological drought, which is a precursor to the other types of drought.

We developed a framework for a drought early warning system (DEWS) exclusively targeting the SADC region. In order to tie the system to regional requirements and ensure sustained operation in the future, we evaluated the preparedness and capacity of SADC countries to monitor drought through a stakeholder needs assessment. We also assessed the spatiotemporal changes in water resources over time to gauge the changes in rainfall patterns and aridity to justify the need for a DEWS. This was achieved by reviewing existing drought intervention mechanisms and institutional arrangements. Historical changes in water resource scenarios were assessed through trends in rainfall and Climate Moisture Index (CMI) to further strengthen the case for a DEWS. The aim was to develop a disaster response framework in response to the recurrence of drought in the region. 


\section{METHODOLOGY}

\section{Description of study area}

The SADC is a southern Africa regional economic community made-up of 15 member states, namely, Angola, Botswana,

Democratic Republic of Congo, Lesotho, Madagascar, Malawi, Mauritius, Mozambique, Namibia, Seychelles, South Africa, Swaziland, Tanzania, Zambia and Zimbabwe (Fig. 1). Thirteen of the member states are on mainland Africa while Madagascar, Mauritius and Seychelles are island states. Of the combined area of 9.86 million $\mathrm{km}^{2}$, only $6.11 \%$ is cultivated (SADC, 2016). Arable land occupies only $5 \%$ of the total regional area. Agriculture is predominantly rainfed, land with irrigation potential covers $\sim 20$ million ha, of which 3.9 million ha is equipped for irrigation, accounting for about $6.6 \%$ of the total cultivated area.

Although $75 \%$ of the SADC region is classified as arid to sub-humid, its climate varies widely from desert to temperate, savannah and equatorial (Devereux, 2007). Decreasing rainfall and increasing temperatures, accompanied by high variability imposed by climate change, cause the region to be classified as a climate hot-spot (Midgley et al., 2002; Thornton et al., 2008). Rainfall patterns are largely governed by the Inter-Tropical Convergence Zone (ITCZ) near the equator, high-pressure cells south of the $20^{\circ}$ parallel, and cold fronts at the southern tip of the African continent. Rainfall distribution is uneven across the region as witnessed from high variability in average annual rainfall, of between 100 and $2000 \mathrm{~mm} /$ year, within the SADC region. The region is drained by 15 transboundary river basins (Fig. 1) with a total mean annual runoff (MAR) of $650 \mathrm{~km}^{3}$ (Malzbender and Earle, 2009).

\section{Drought early warning system (DEWS) methodological framework}

Figure 2 is a methodological flowchart that was followed to achieve the study goals, assess drought recurrence in the SADC and develop a regional DEWS framework. The study addressed the key areas of a drought early warning system (DEWS) which include: (i) drought risk knowledge, (ii) forecasting and monitoring, (iii) dissemination, and (iv) response capabilities. Drought and rainfall trends were analysed to assess the level of drought risk in the region. A user needs assessment survey was carried out in selected countries that were the most affected by the 2015/16 drought to assess impact and institutional capacity to mitigate and manage droughts. An evaluation of the effectiveness of existing EWS was done based on the country surveys and literature review, to identify synergies and enhance drought early warning and management in the region as part of building predictive capacity and dissemination. With respect to drought-risk knowledge, the study analysed the level of risk posed by water, energy and food insecurity in southern Africa. With respect to drought frequency and level of drought risk the study used two indicators, mainly rainfall and aridity, to assess changes that have taken place over time. The study assessed regional needs through a survey of some regional countries where the existence and effectiveness of drought policies and water resources information systems (WRIS) as elements of drought resilience initiatives were assessed. The study also evaluated institutional needs and capacity and the role of regional and international organisations in drought monitoring and assessment. An assessment of the effectiveness of existing DEWS as well as their shortcomings was done. The assessment

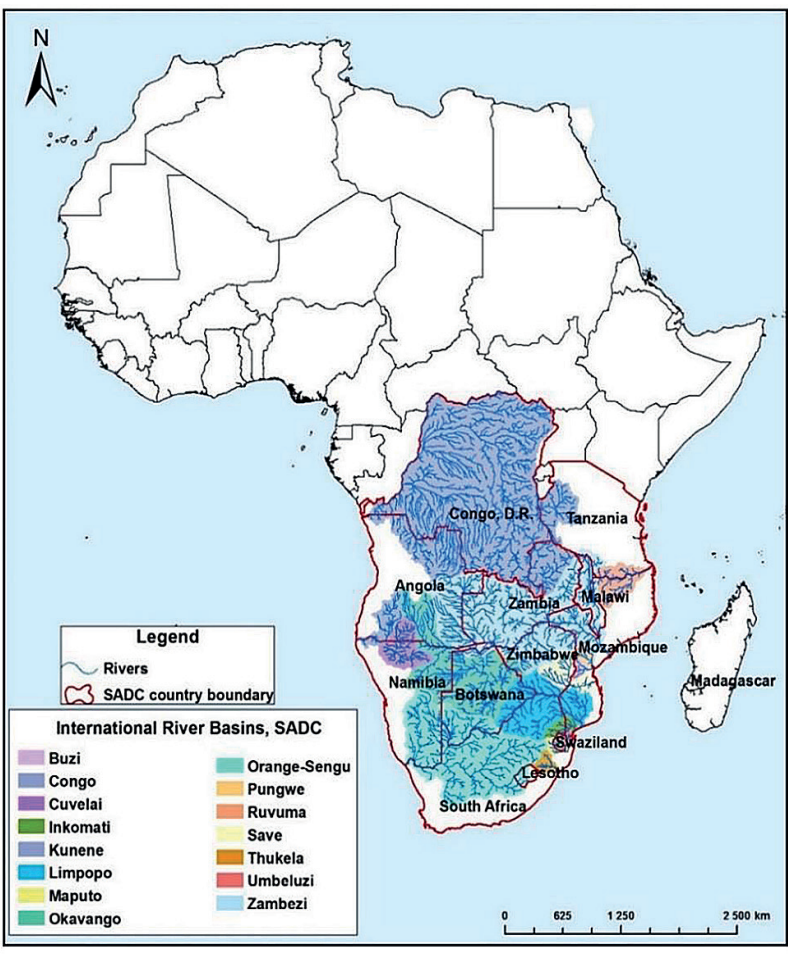

Figure 1

$S A D C$ countries within the African continent and the transboundary river basins within the bloc

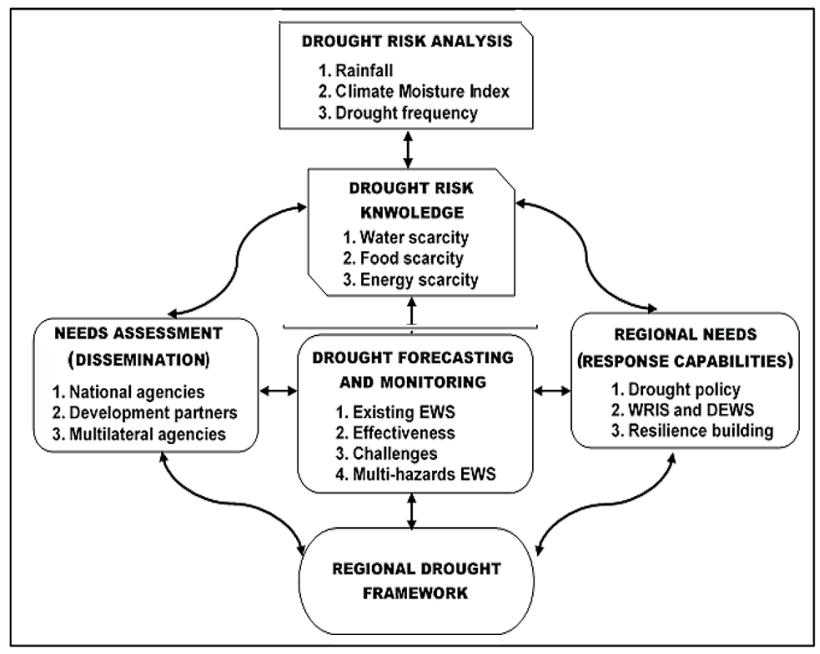

Figure 2

Methodological flowchart for drought assessment in the SADC region. Note: WRIS - Water Resources Information System; DEWS - Drought Early Warning System.

culminated with the development of a regional drought early warning system framework, which took into consideration regional characteristics and challenges.

\section{Assessing changes in inter-annual rainfall distribution and trends in the SADC region}

Monthly rainfall records from 1960 to 2007 were analysed to assess changes in rainfall distribution in the SADC region over selected years. Records before 1960 were not used as they had 
data gaps that would not allow a representative analysis during interpolation. Records from 2008 to more recent years were not readily available. The Tropical Rainfall Measurement Mission (TRMM) and Global Precipitation Measurement (GPM) data could have been an option for this analysis but the records only start from 1997, whereas the objective was to make a long-term analysis.

Observed rainfall records from 908 stations (http://www. fao.org/nr/climpag/data_2_en.asp) were used to calculate average annual rainfall for each SADC country. Time series and continuous rainfall maps that were developed were essential in understanding the spatio-temporal changes in rainfall distribution. The inverse distance weighting (IDW) interpolation method (Chen and Liu, 2012) was used to create rainfall maps using geographic information systems (GIS). The area-weighted average method was used to calculate the average annual rainfall of each country using Thiessen's polygon method (Thiessen, 1911). Thiessen's polygon method tessellates an area into regions that are closer to a particular station than to any other. To average rainfall values in the created Thiessen polygons over each country, the Thiessen polygons were intersected with the country boundary in GIS, from where the area-weighted average was calculated. Country areas were multiplied with the respective country total annual rainfall and summed up, and then divided by the total geographical area of SADC to get the regional area-weighted average rainfall.

\section{Assessing aridity through the Climatic Moisture Index (CMI)}

The degree of aridity (water stress or scarcity) was assessed using the Climatic Moisture Index (CMI) (Eqs 1 and 2), an index of the relative dryness or wetness of an area (Willmott and Feddema, 1992). Observed monthly precipitation and evapotranspiration (ET) records from 1980 to 2007 were analysed to assess the region's level of aridity. ET records before 1980 and after 2007 were not available. Remote sensing products on ET such as the MODIS Global Evapotranspiration Project (MOD16) and Global Land Evaporation Amsterdam Model (GLEAM) started only recently and lack long-term data records.

The CMI is widely and successfully used in assessing drought (Ma et al., 2012; Malisawa and Rautenbach, 2012), and is expressed as:

$$
\begin{aligned}
& \mathrm{CMI}=\frac{P}{P E T}-1, \text { when } P<P E T, \text { and } \\
& \mathrm{CMI}=1-\frac{P E T}{P}, \text { when } P \geq P E T
\end{aligned}
$$

where $P E T$ is potential evapotranspiration and $P$ is precipitation.
The CMI was used to determine the water stress or scarcity of the region, the basis for initiating resilience building processes. The index ranges from -1 to +1 , with wet and dry climates showing positive and negative CMI, respectively. The CMI is an aggregate measure of potential water availability imposed solely by climate. The PET of each country was calculated from data recorded from weather stations within the region and the results interpolated in GIS to create a continuous PET surface. Thiessen's polygon was then used to calculate the area-weighted average PET for each country. The CMI was calculated for 1980, 1990, 2000 and 2007 and the results were used to assess changes in water scarcity in the region over the years.

\section{Consultation through user needs survey}

A user needs analysis was carried out in four SADC countries that had declared states of emergency during the 2015/16 drought and were deemed the most affected by the drought. The consultation centred on discussions and key informant interviews with targeted stakeholders in Madagascar, Malawi, Zambia and Zimbabwe. Consulted stakeholders included specialists in disaster management and drought early warning. These consisted of government departments, non-governmental organisations (NGOs), academia and multi-lateral development organisations. An interview guide questionnaire formed the basis for discussions with stakeholders. The questions focused on the impact of the 2015/16 El Niño drought as a reference year. The questionnaire also touched on existing early warning programmes and their operational methodologies, hydrometeorological data availability and accessibility, human and institutional capacity and arrangement, coordination of disaster management activities, user needs analysis, livelihoods, and gender issues. An average of 20 stakeholders were consulted in each country visited. The outcomes were aggregated to construct the specifics of DEWS and were used as a basis for the regional DEWS framework.

\section{RESULTS AND DISCUSSION}

\section{Drought trends in Africa in comparison with the rest of the world}

From 1900 to 2016, the EM-DAT database included 702 recorded drought events worldwide, and 312 of these occurred in Africa (Table 2) (Guha-Sapir et al., 2017). Thus, the African continent is the most affected by drought occurrences. Since 1900 , drought has taken a huge toll on humanity, killing about 12 million people and affecting over 3 billion people (GuhaSapir et al., 2017). The total economic damage is estimated at

\begin{tabular}{|l|c|c|c|c|}
\hline \multicolumn{5}{|c|}{$\begin{array}{c}\text { TABLE 2 } \\
\text { Number of droughts and their impact across the world during 1900-2013 } \\
\text { (Source: EM-DAT: The International Disaster Database; Guha-Sapir et al., 2017) }\end{array}$} \\
\hline Continent & No. of events & No. of people killed & No. of people affected & Total damage ('000 USD) \\
\hline Africa & 312 & 867131 & 414235329 & 6428593 \\
\hline Americas & 152 & 77 & 109375181 & 59671139 \\
\hline Asia & 167 & 9663400 & 2107113716 & 42718264 \\
\hline Europe & 42 & 1200002 & 15488769 & 25481309 \\
\hline Oceania & 29 & 684 & 10742019 & 11586000 \\
\hline Total & 702 & 11731294 & 2656955014 & 145885305 \\
\hline
\end{tabular}


146 billion USD (Table 2). These statistics justify the need for a dedicated DEWS to mitigate drought impact in Africa.

Figure 3 shows the average number of drought events that occurred in 7 SADC countries between 1960 and 2016. Malawi, Madagascar, Mozambique and Zimbabwe were the most affected countries where, on average, drought occurs once in every 3 years (Guha-Sapir et al., 2017).

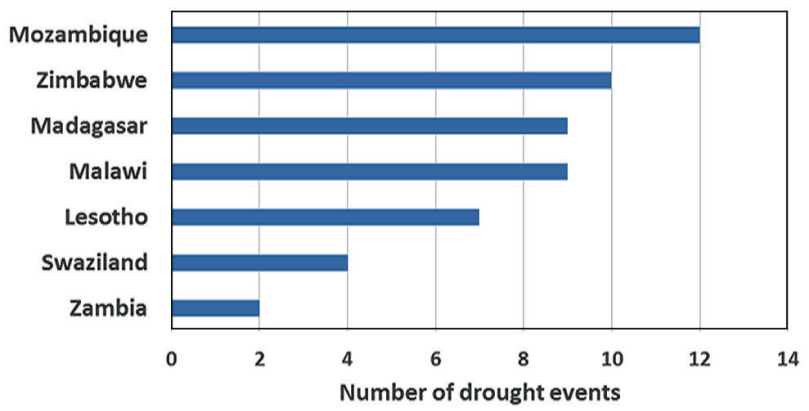

Figure 3

Average number of drought events in selected SADC countries from 1960 to 2016. Source: Author construction from EM-DAT (Guha-Sapir et al., 2017)

\section{Spatio-temporal changes in rainfall distribution in the SADC region}

The spatio-temporal changes in annual rainfall distribution in the SADC region are indicated in Fig. 4a (1960), 4b (1970), 4c (1980), 4d (1990), 4e (2000) and 4f (2007). The spatio-temporal maps for rainfall show significant changes that occurred in the region during the 47 years under review (Fig. 4). Total annual rainfall declined to unprecedented levels, from $1200 \mathrm{~mm}$ to $890 \mathrm{~mm}$ between 1960 and 2007. Almost half of the regional surface area has become arid (Nicholson, 2001), receiving less than $650 \mathrm{~mm}$ of rainfall (Fig. 4f). Generally, the region is marked by great spatio-temporal rainfall variability, particularly in the drier southern countries. The decreasing rainfall over the years signifies an increasingly drying region. Statistical analysis showed that rainfall in the region decreased by $25.6 \%$ between 1960 and 2007, highlighting the worsening aridness and water scarcity of the region.

A further analysis of rainfall data over time (Fig. 5) showed that rainfall was highly variable in the region as shown by the fluctuations on the graph. The variability has intensified over the recent past, accompanied by decreasing rainfall totals (Fig. 5). The decreasing rainfall and variability were ascertained by the Mann-Kendall trend test, which showed a significant

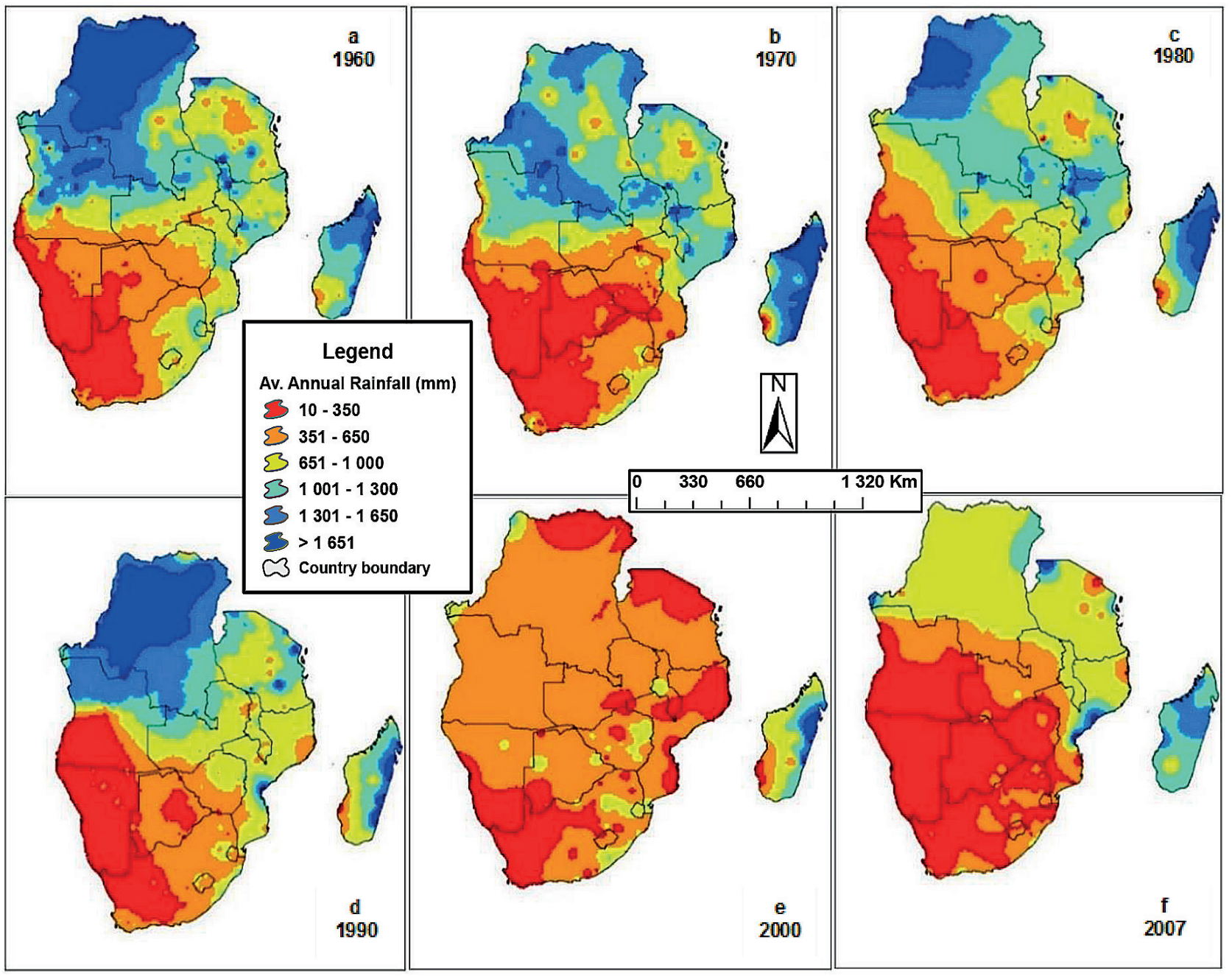

Figure 4

Spatio-temporal changes in annual rainfall distribution in the SADC region for selected years 


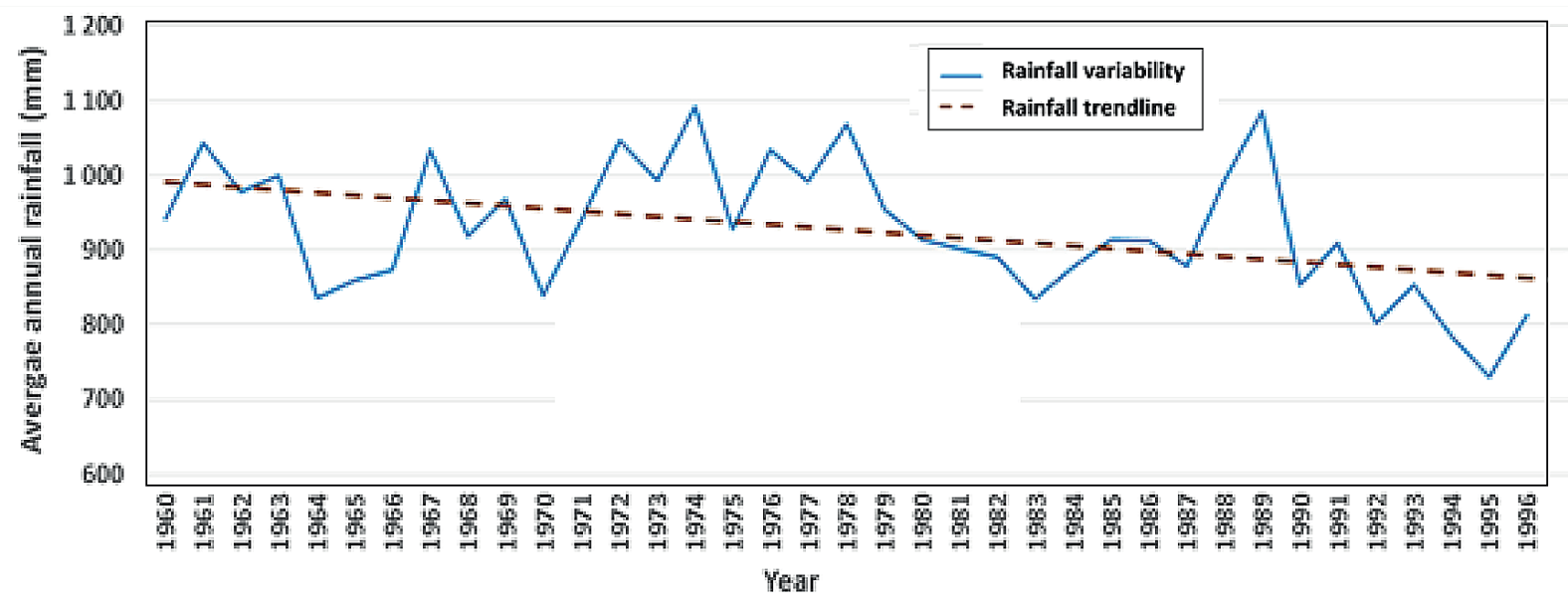

Figure 5

Rainfall variability and trend in the SADC region from 1960 to 1996

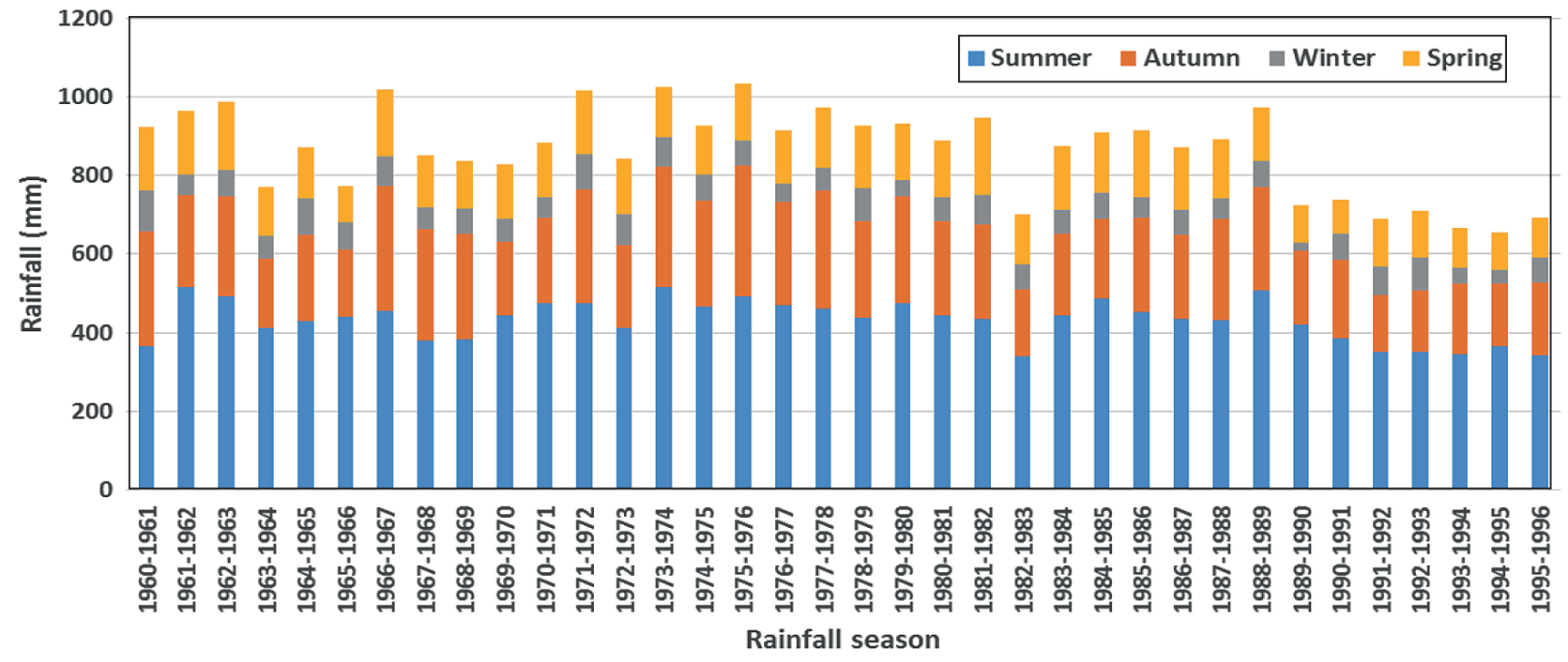

Figure 6

Temporal change in annual and seasonal rainfall in the SADC region from 1960 to 1996

decreasing trend $(\alpha<0.01)$ in rainfall totals in the SADC region for the period under review.

Figure 6 presents the area-weighted annual average rainfall by season (summer, autumn, winter and spring) from 1960 to 1996 for the SADC region. In southern Africa, the summer season (December to February) is the wettest and winter (June to August) is the driest (Davis and Vincent, 2017). Autumn (March to May) and spring (September to November) are generally transitional seasons ushering into winter and summer, respectively (Davis and Vincent, 2017). The region's rainfall is marked by high variability from 1960-1961 to 1988-1989 (Fig. 6). However, from 1989/90 onwards the variability is accompanied by a continued decrease in rainfall totals, particularly during summer. Drought recurrence and intensity during this period explains the decreasing rainfall, as also evidenced in Figs. 4 and 5 and as reported by Davis and Vincent (2017). The decline in summer rainfall from 1989/1990 onwards explains the low crop yields (Table 1), as agriculture is mainly rainfed.

\section{Degree of aridity and water scarcity in the SADC region}

The spatio-temporal changes in aridity or water scarcity over time (1980-2007) in the SADC region, calculated through CMI, is shown in Fig. 7. The CMI values are negative or below 0 , indicating that PET exceeds precipitation. According to Vörösmarty et al. (2005), there is a classification link between CMI values and climatic conditions $(\mathrm{CMI}<-0.6=$ arid; $-0.6<$ $\mathrm{CMI}<0=$ semi-arid; $0>\mathrm{CMI}<0.25=$ sub-humid and $\mathrm{CMI}>$ $0.25=$ humid). The average CMI for the region was calculated at -0.80 , qualifying the region to be arid and water scarce. The average CMI complements results from previous studies (Malisawa and Rautenbach, 2012). The aridness is increasing with time (Fig. 7), a bad situation for agriculture and energy, two sectors where water plays a crucial role as an input to the production system. Overall, aridity in the region increased by $10.8 \%$ during the period under review, highlighting the worsening aridity and water scarcity in the region. 


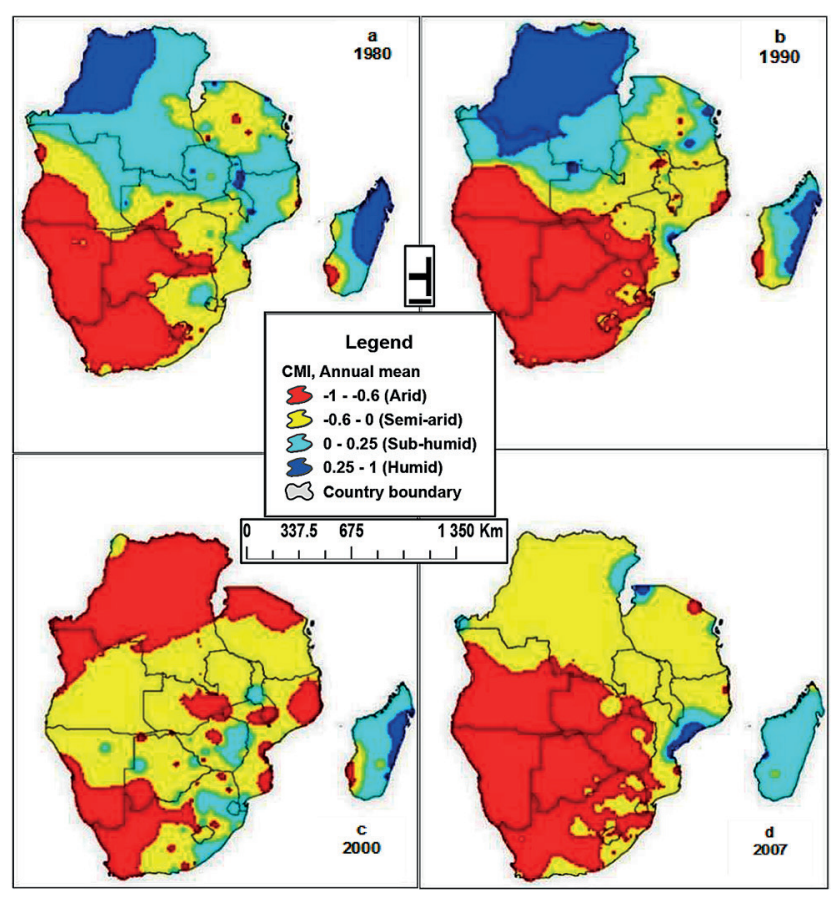

Figure 7

Spatio-temporal changes in water scarcity and aridity in the SADC region

\section{Needs assessment survey}

The results of the user needs assessment showed that, of the four sampled countries (Madagascar, Malawi, Zambia and Zimbabwe), none had a drought policy nor a dedicated DEWS (Table 3). Table 3 provides a detailed assessment of institutional and legal frameworks in each of the sampled countries. Although the countries have institutional frameworks in place, they are poorly equipped and lack human capacity to efficiently monitor and forecast droughts. As a result, the sampled countries have low levels of drought preparedness although each of them has a disaster management institution. The low level of preparedness are evidenced by the reactive interventions during drought events. A good example is the 2015/16 drought in which the whole region was caught unawares, resulting in 40 million people becoming food insecure, requiring 2.7 billion USD in international assistance (SADC, 2016). It was also observed that most of the existing EWS in the sampled countries were multi-hazard, and tended to focus on a few hazards, leaving out more complex ones like drought. Also of note in the sampled countries is the presence of water institutions/departments, meteorological and disaster management institutions. At regional level, the SADC Secretariat has a Regional Early Warning Unit (REWU) which is multi-hazard. The assessment helped in identifying national centres and a regional hub where an operational drought monitoring system could be domiciled.

The needs assessment also observed that hydrometeorological stations were sparse and limited. In addition, the majority of these hydro-meteorological stations are old and non-functional. This hinders effective observation and monitoring and the development of an early warning system (EWS). Nevertheless, the advent of remote sensing and GIS as well as numerical modelling has made it possible to monitor drought and other disasters even at local level. As noted, current operational EWS (Table 4) use remote sensing products to monitor disasters and generally lack the forecasting component. The most notable is the Famine Early Warning System Network (FEWS-NET), a programme of the United States Agency for International Development (USAID) focusing on the region and with country offices in the region (Verdin et al., 2005). The system employs a livelihoods framework to geographically characterise vulnerability and interpret hazards (drought, floods, cyclones, etc.), and provides decadal and monthly reports. As part of the FEWS-NET, the National Atmospheric Administration (NOAA), United States Geological Survey (USGS), and National Aeronautics and Space Administration (NASA) provide routine reviews of a suite of monitoring and assessment products to produce a weekly Africa Weather Hazards Assessment (AWHA). The reports are distributed to partners and posted on the FEWS-NET website (Verdin et al., 2005).

One other recent EWS initiative is the SADC MESA (Monitoring for the Environment and Security in Africa), which is a follow-up to the African Monitoring of the Environment for Sustainable Development (AMESD) programme. The MESA programme uses remote sensing

\begin{tabular}{|l|c|c|c|}
\hline \multicolumn{5}{|c|}{$\begin{array}{c}\text { TABLE } 4 \\
\text { region } \\
\text { rome of the drought early warning initiatives in the SADC }\end{array}$} \\
\hline Name & Source & Purpose & Coverage \\
\hline FEWS-NET & NASA/USAID & Multi-hazard & Regional \\
\hline SADC-MESA & AMESD & Multi-hazard & Regional \\
\hline DEWFORA & EU/DANIDA & Drought & Some IRBs \\
\hline REWS & SADC & Multi-hazard & Regional \\
\hline GIEWS & FAO & Food security & Global \\
\hline HEWS & WFP & Multi-hazard & Global \\
\hline ADO & EU JRC & Drought & Africa \\
\hline
\end{tabular}

\section{TABLE 3}

Needs assessments survey results from four SADC countries

\begin{tabular}{|l|l|l|l|l|l|l|l|}
\hline Country & $\begin{array}{l}\text { Water } \\
\text { institution }\end{array}$ & $\begin{array}{l}\text { Disaster } \\
\text { institution }\end{array}$ & $\begin{array}{l}\text { Level of } \\
\text { preparedness }\end{array}$ & $\begin{array}{l}\text { Weather } \\
\text { institution }\end{array}$ & DEWs & $\begin{array}{l}\text { Multi-hazard } \\
\text { EWS }\end{array}$ & $\begin{array}{l}\text { Drought } \\
\text { policy }\end{array}$ \\
\hline Madagascar & Yes & Yes & Low & Yes & No & Yes & No \\
\hline Malawi & Yes & Yes & Low & Yes & No & Yes & No \\
\hline Zambia & Yes & Yes & Low & Yes & No & Yes & No \\
\hline Zimbabwe & Yes & Yes & Low & Yes & No & Yes & No \\
\hline SADC & Yes & Yes & Low & Yes & No & Yes & No \\
\hline
\end{tabular}

Key: 'Yes' signifies the presence of the category and 'No' signifies its absence 
products to monitor the environment in general, including drought, floods, agriculture and fires, in near real-time. On drought, the programme uses remote sensing data to monitor and model drought conditions during the whole year and provides regular 10-day drought maps and monthly drought risk forecasts. Other EWS initiatives identified during the needs assessment (Table 4) include the Global Information and EWS (GIEWS), which is a product of the Food and Agriculture Organisation (FAO), and the Humanitarian EWS (HEWS) which is a product of the World Food Programme (WFP). Similar to FEWS-NET, these have a large coverage (global and sub-regional) and generally target global users. Also, the Drought Early Warning System for Africa (DEWFORA) programme uses drought indicators to monitor and forecast drought for some river basins, including the Limpopo River Basin. Scientific methods generally used in meteorological drought monitoring include; Water Requirement Satisfactory Index (WRSI), Standardised Precipitation Index (SPI), Normalised Difference Vegetation Index (NDVI), and Weather/Seasonal Rainfall Forecasts. It was noted that existing multi-hazards EWS in southern Africa do not provide sufficient information on drought forecasting to prepare for an imminent drought, focusing mainly on drought severity, duration and frequency (Miyan, 2015; Muller et al., 2015). The proposed DEWS is thus a pathway to build resilience as forecasting informs policy by advance warning of an imminent drought.

\section{Drought forecasting and monitoring models}

Drought recurrence, which has intensified in recent years, has emerged as one of the biggest challenges facing southern Africa. A combination of increasing drought frequency and intensity, increasing aridity, decreasing rainfall and lack of institutional capacity increase the vulnerability of the region. Lack of a DEWS that includes the forecasting component has only exacerbated the situation. Whilst monitoring and assessing an ongoing drought event is vital, as already being done by existing DEWS, a complete system should also be

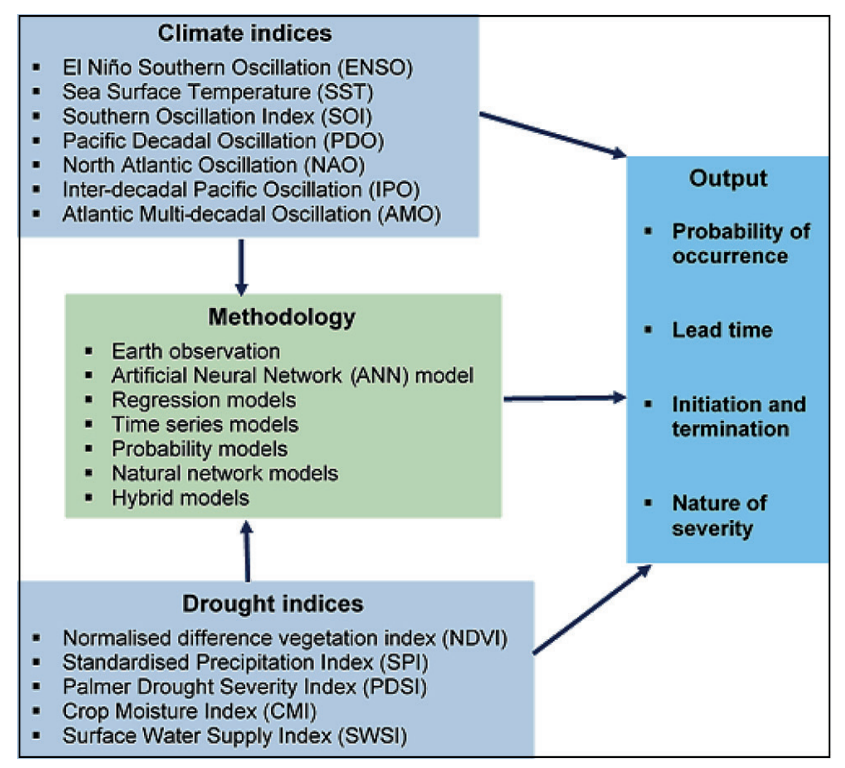

Figure 8

Components of a drought early warning system methodology (Adapted from Mishra and Singh, 2011) capable of providing information on the pending drought and provide sufficient lead-time for decision-makers to plan. There have been efforts to forecast droughts using models and indices shown in Fig. 8 (Mishra and Singh, 2011). The use of earth observation (EO) technologies to monitor changes in ocean currents and temperature, coupled with methods like artificial neural networks (ANN), together with climate and drought indices, have made in-roads in drought forecasting and are being applied successfully in other regions (Morid et al., 2007; Özger et al., 2012). Remote sensing products such as the NDVI, in combination with other models, have been very useful in monitoring and assessing ongoing drought conditions on a weekly basis (http://dms.iwmi.org/), but long-term drought forecasting still lags behind. Further research is needed to improve on long-term forecasting. Drought forecasting and monitoring is being used as a base to develop weather indexbased insurance for smallholder farmers, which has potential to increase the resilience of marginalised communities (Carter et al., 2014; Tadesse et al., 2015).

As already alluded to, current EWS are generally multihazard, thus their inadequacy to provide reliable drought forecasts. For example, drought alerts from the Regional Early Warning System (REWS) are only conveyed during the course of a disaster leaving little or no time for mitigation (Rook, 2005). The REWS assesses the impact of weather conditions on crop production prospects and, hence, on the food supply situation. It gets information from country Early Warning Units (EWU) and therefore, says little, if anything, about the pending weather conditions or harvest prospects until the growing season gets under way. An effective DEWS should give enough lead-time and provide relevant information at local level (Pozzi, et al., 2013). A DEWS is, thus, an integral part of resilience building and sustainable development providing information on:

- The extent of the pending drought and possible number of people that could be affected

- The extent of food and water scarcity and a suggested response (proactive)

- Strategy to address the problem within a drought plan

\section{Drought early warning system framework for southern Africa}

A DEWS provides decision-makers and stakeholders with evidence to plan, monitor and evaluate drought impact. It is a tool to forecast and monitor droughts and mitigate droughts from becoming disasters (Pulwarty and Sivakumar, 2014; WMO, 2006). Drought resilience and preparedness are highly dependent on the reliability of early warning information that is provided, something that is currently lacking in the region. Advances in remote sensing are enabling forecasting and monitoring of drought and related information at local level. Space-based technologies have potential to change drought forecasting and response from disaster recovery to disaster prevention (UNISDR, 2009). Drought forecasts and preparedness reduce drought vulnerability and foster droughtresilient societies. Thus, a DEWS framework was built based on the following five interlinked components:

- Drought risk reduction through good processes and practices, which is central to the framework. This central component comprises of (i) a drought information dissemination system (DIDS) to inform stakeholders of a looming drought and the impact of an ongoing drought, and (ii) resilience building through growing 
drought-tolerant crops, rainwater harvesting, among others.

- Policy and governance to direct drought risk management and provide political commitment. Policy is important for resource allocation. The current lack of drought policy and strategies among regional states often means that there are no dedicated resources; hence resources always have to be mobilised from elsewhere thus compromising implementation of other government programmes.

- Drought early warning, which includes (i) drought forecasting and monitoring, (ii) impact assessment and (iii) drought information dissemination system (DIDS). The early warning system gives enough lead time to assess possible impacts for decision-making. This component is anchored by the methods used in drought early warning and the water resources information system (WRIS)

- Public awareness and engagement to cultivate a culture of drought risk reduction and co-develop resilient communities. This component includes drought awareness campaigns, participatory processes and drought dissemination.

- Mitigation and preparedness as a step to build resilience through various drought risk reduction initiatives such as water harvesting, dam construction, growing indigenous crops that are adapted to local harsh conditions, access to clean and safe water, and adoption of a WEF nexus approach, among others.
Figure 9 illustrates the DEWS conceptual framework for southern Africa conditions, showing the five components and their elements. The system forecasts drought conditions through a combination of hydrological modelling, earth observation and seasonal climate forecasts. A Water Resources Information System (WRIS) provides information on both ground and surface water, soil moisture condition, vegetation and crop health as part of the DEWS. Crop condition monitoring is part of the DEWS as it gives an indication on crop yield estimates, an important component of famine early warning, The DIDS is an integral part of the DEWS for the timely dissemination of drought and agro-meteorological information to stakeholders.

\section{CONCLUSIONS}

Drought disasters in southern Africa are mainly attributed to lack of preparedness, poor response and mitigation and poor risk reduction mechanisms. Analysed data from 1960 to 2007 showed an increasing frequency and intensity of drought, as well as rainfall variability, which contribute to regional food and water insecurity. These challenges accentuate the vulnerability of the region and amplify the humanitarian crisis whenever there is drought. Drought recurrence in a region with limited resources to cope, coupled by the dependence on climate-sensitive sectors of agriculture, hydro-energy and fisheries, exacerbates the humanitarian crises. Drought

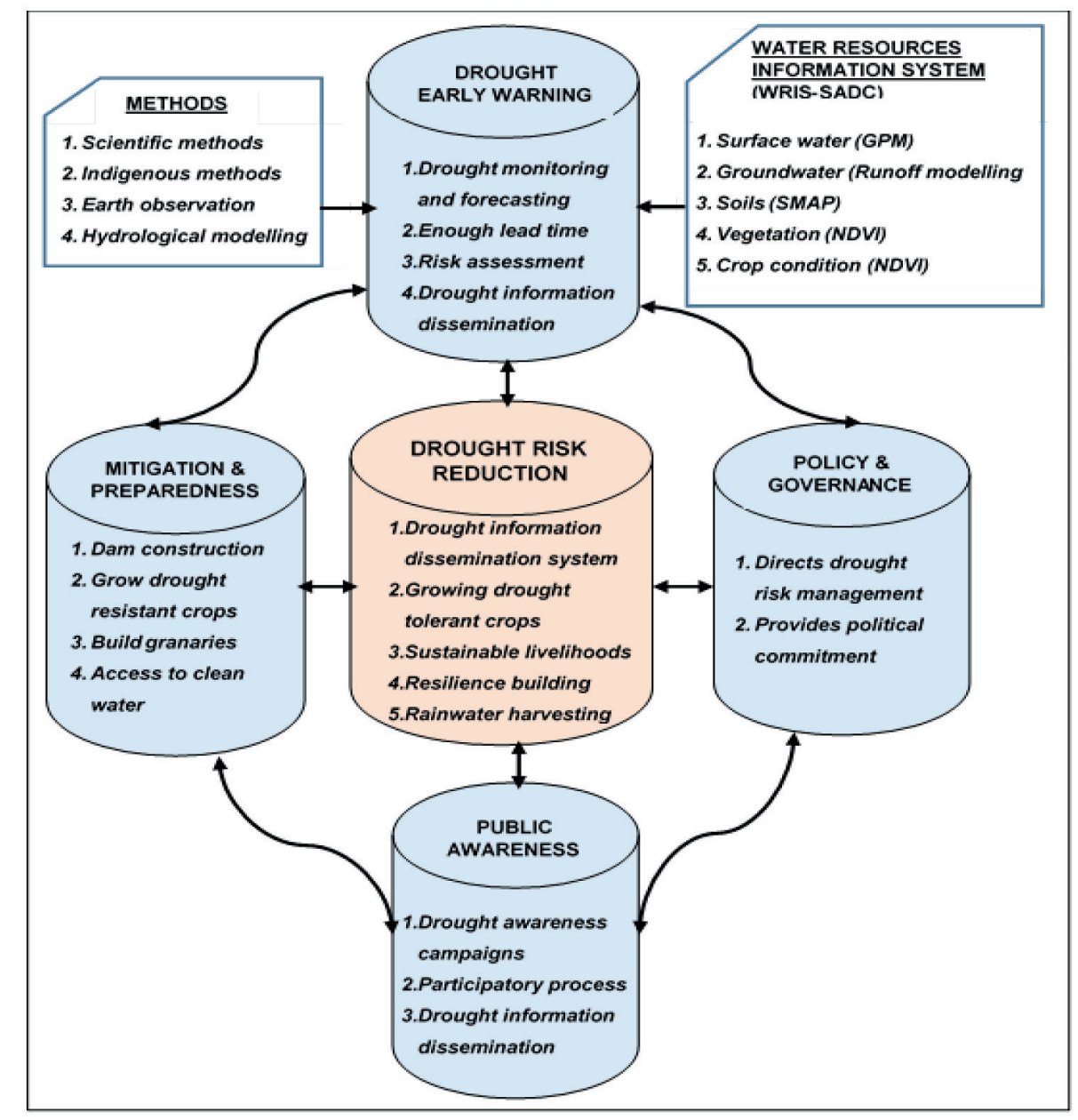

Figure 9

Components of a drought early warning system framework for SADC region 
events occur more often in Africa than other regions of the world, yet the present drought mitigation mechanisms are limited in capacity to give enough quantitative information and sufficient lead-time for decision makers to plan or make informed decisions on drought intervention. Governments have less control over the operations of current mechanisms as they wait to be informed by third parties, delaying the decision-making process, thus resulting in interventions being reactive instead of proactive. A regionally focused drought forecasting and monitoring system would provide enough tools for drought mitigation as a pathway towards the formation of resilient communities. Drought forecasting and monitoring are a priority in preventing further loss of life and livestock in the advent of climate change. Although the effectiveness of early warning systems has been limited by ageing and non-functional hydrometric equipment, the advent of remote sensing has improved drought monitoring and provision of agro-meteorological information in near real-time in some regions. With the increasing frequency and intensity of droughts, a paradigm shift from focusing only on relief aid post-disaster to preparedness and resilience building should be preferred in order to reduce vulnerabilities.

\section{ACKNOWLEDGEMENTS}

The authors would like to thank the International Water Management Institute (IWMI), The Food and Agriculture Organisation of the United Nations (FAO) and the University of KwaZulu-Natal (UKZN) for supporting the research project on drought assessment in the SADC region and facilitating time to write the manuscript.

\section{REFERENCES}

AGHAKOUCHAK A, FARAHMAND A, MELTON F, TEIXEIRA J, ANDERSON M, WARDLOW BD and HAIN C (2015) Remote sensing of drought: Progress, challenges and opportunities. Rev. Geophys. 53 (2) 452-480. https://doi.org/10.1002/2014RG000456

BASU S, RAMEGOWDA V, KUMAR A and PEREIRA A (2016) Plant adaptation to drought stress. F1000Research 1 (5) 1554. https://doi. org/10.12688/f1000research.7678.1

CARTER M, DE JANVRY A, SADOULET E and SARRIS A (2014) Index-based weather insurance for developing countries: A review of evidence and a set of propositions for up-scaling. Development Policies Working Paper, Paris, France.

CHEN F-W and LIU C-W (2012) Estimation of the spatial rainfall distribution using inverse distance weighting (IDW) in the middle of Taiwan. Paddy Water Environ. 10 (3) 209-222. https://doi. org/10.1007/s10333-012-0319-1

DAVIS CL and VINCENT K (2017) Climate Risk and Vulnerability: A Handbook for Southern Africa ( $2^{\text {nd }}$ edn). CSIR, Pretoria, South Africa.

DE WAAL J and VOGEL C (2016) Disaster risk profiling in southern Africa: inventories, impacts and implications. Nat. Hazards 84 (3) 1921-1942. https://doi.org/10.1007/s11069-016-2527-2

DEVEREUX S (2007) The impact of droughts and floods on food security and policy options to alleviate negative effects. Agric. Econ 37 (s1) 47-58. https://doi.org/10.1111/j.1574-0862.2007.00234.x

FAITHPRAISE F, IDUNG J, CHATWIN C, YOUNG R and BIRCH P (2015) Modelling the control of African Armyworm (Spodoptera exempta) infestations in cereal crops by deploying naturally beneficial insects. Biosyst. Eng. 129 268-276. https://doi. org/10.1016/j.biosystemseng.2014.11.001

FAO (2016) Global Information and Early Warning System (GIEWS). in Country Briefs, Food and Agriculture Organisation of the United Nations (FAO), Rome, Italy.

FAO (2016) The State of Food and Agriculture, 2016: Food Aid for Food Security?, Food and Agriculture Orginsation of the United Nations
(FAO). Rome, Italy.

GIZAW MS and GAN TY (2016) Impact of climate change and El Niño episodes on droughts in sub-Saharan Africa. Clim. Dyn. 49 (1-2) 665-681.

GUHA-SAPIR D, BELOW R and AND HOYOIS P (2017) The international disaster database. Centre for Research on the Epidemiology of Disasters (CRED): The CRED/OFDA International Disaster Database, Université Catholique de Louvain. in CRED/ OFDA Ts (ed), Brussels, Belgium.

HAO Z, AGHAKOUCHAK A, NAKHJIRI N and FARAHMAND A (2014) Global integrated drought monitoring and prediction system. Sci. Data 1 140001. https://doi.org/10.1038/sdata.2014.1

LAMBOLL R, NELSON V and NATHANIELS N (2011) Emerging approaches for responding to climate change in African agricultural advisory services: Challenges, opportunities and recommendations for an AFAAS climate change response strategy. AFAAS, Kampala, Uganda and FARA, Accra, Ghana.

MA Z, PENG C, ZHU Q, CHEN H, YU G, LI W, ZHOU X, WANG W and ZHANG W (2012) Regional drought-induced reduction in the biomass carbon sink of Canada's boreal forests. Proc. Natl Acad. Sci. 109 (7) 2423-2427. https://doi.org/10.1073/pnas.1111576109

MALISAWA M and RAUTENBACH CDW (2012) Evaluating water scarcity in the Southern African Development Community (SADC) region by using a climate moisture index (CMI) indicator. Water Sci. Technol. Water Suppl. 12 (1) 45-55. https://doi.org/10.2166/ ws.2011.113

MALZBENDER D and EARLE A (2009) Water Resources of the SADC: Demands, Dependencies and Governance Responses.

MARIOTTI A, SCHUBERT S, MO K, PETERS-LIDARD C, WOOD A, PULWARTY R, HUANG J and BARRIE D (2013) Advancing drought understanding, monitoring, and prediction. Bull. Am. Meteorol. Soc. 94 (12) ES186-ES188. https://doi.org/10.1175/ BAMS-D-12-00248.1

MIDGLEY G, HANNAH L, MILLAR D, RUTHERFORD M and POWRIE L (2002) Assessing the vulnerability of species richness to anthropogenic climate change in a biodiversity hotspot. Glob. Ecol. Biogeogr. 11 (6) 445-451. https://doi. org/10.1046/j.1466-822X.2002.00307.x

MISHRA AK and SINGH VP (2011) Drought modeling - A review. J. Hydrol. 403 (1-2) 157-175. https://doi.org/10.1016/j. jhydrol.2011.03.049

MIYAN MA (2015) Droughts in Asian least developed countries: vulnerability and sustainability. Weather Clim. Extremes 7 8-23. https://doi.org/10.1016/j.wace.2014.06.003

MORID S, SMAKHTIN V and BAGHERZADEH K (2007) Drought forecasting using artificial neural networks and time series of drought indices. Int. J. Climatol. 27 (15) 2103-2111. https://doi org/10.1002/joc.1498

MULLER M, CHIKOZHO C and HOLLINGWORTH B (2015) Water and Regional Integration: The role of water as a driver of regional economic integration in Southern Africa. WRC Report No. 2252/1/14. Water Research Commission, Pretoria.

NHAMO L, NDLELA B, NHEMACHENA C, MABHAUDHI T, MPANDELI S and MATCHAYA G (2018) The water-energy-food nexus: climate risks and opportunities in Southern Africa. Water 10 (567) 18. https://doi.org/10.3390/w10050567

NICHOLSON SE (2001) Climatic and environmental change in Africa during the last two centuries. Clim. Res. 17 (2) 123-144. https://doi. org/10.3354/cr017123

OSBAHR H (2007) Building resilience: Adaptation mechanisms and mainstreaming for the poor. Human Development Report 2007/2008. Fighting climate change: Human solidarity in a divided world. Human Development Report Office Occasional Paper. March 2007. UNDP. URL: http://hdr.undp.org/sites/default/files/ osbahr_henny.pdf (Accessed 15 August 2017).

ÖZGER M, MISHRA AK and SINGH VP (2012) Long lead time drought forecasting using a wavelet and fuzzy logic combination model: A case study in Texas. J. Hydrometeorol. 13 (1) 284-297. https://doi.org/10.1175/JHM-D-10-05007.1

POZZI W, SHEFFIELD J, STEFANSKI R, CRIPE D, PULWARTY R, VOGT JV, HEIM JR RR, BREWER MJ, SVOBODA M and WESTERHOFF R (2013) Toward global drought early warning capability: Expanding international cooperation for the 
development of a framework for monitoring and forecasting. Bull. Am. Meteorol. Soc. 94 (6) 776-785. https://doi.org/10.1175/ BAMS-D-11-00176

PULWARTY RS and SIVAKUMAR MV (2014) Information systems in a changing climate: Early warnings and drought risk management. Weather Clim. Extremes 3 14-21. https://doi.org/10.1016/j. wace.2014.03.005

ROOK J (2005) The SADC regional early warning system: Experience gained and lessons learnt from the 1991-92 Southern Africa drought. In: Glantz MHs (ed) Using Science Against Famine: Food Security, Famine Early Warning and El Niño. Cambridge University Press, Colorado, USA 163 pp.

SADC (Southern African Development Community) (2016) Regional Strategic Action Plan on Integrated Water Resources Development and Management Phase IV. SADC, Gaborone.

SADC (Southern African Development Community) (2016) SADC Regional Humanitarian Appeal, June 2016. Secretariat S, Gaborone, Botswana.

SCHULZE R (2012) A 2011 perspective on climate change and the South African water sector. WRC Report No. 1843/2/11. Water Research Commission, Pretoria.

SHEFFIELD J, WOOD EF, CHANEY N, GUAN K, SADRI S, YUAN X, OLANG L, AMANI A, ALI A and DEMUTH S (2014) A drought monitoring and forecasting system for sub-Sahara African water resources and food security. Bull. Am. Meteorol. Soc. 95 (6) 861-882. https://doi.org/10.1175/BAMS-D-12-00124.1

TADESSE MA, SHIFERAW BA and ERENSTEIN O (2015) Weather index insurance for managing drought risk in smallholder agriculture: lessons and policy implications for sub-Saharan Africa. Agric. Food Econ. 3 (1) 26. https://doi.org/10.1186/ s40100-015-0044-3

THIESSEN AH (1911) Precipitation averages for large areas. Mon. Weather Rev. 39 (7) 1082-1089. https://doi. org/10.1175/1520-0493(1911)39<1082b:PAFLA>2.0.CO;2

THORNTON PK, JONES PG, OWIYO T, KRUSKA RL, HERRERO M, ORINDI V, BHADWAL S, KRISTJANSON P, NOTENBAERT A and BEKELE N (2008) Climate change and poverty in Africa: Mapping hotspots of vulnerability. Afr. J. Agric. Resour. Econ. 2 (1) 24-44.
TIRADO M, HUNNES D, COHEN M and LARTEY A (2015) Climate change and nutrition in Africa. J. Hunger Environ. Nutr. 10 (1) 22-46. https://doi.org/10.1080/19320248.2014.908447

UNISDR (2009) Drought Risk Reduction Framework and Practices: Contributing to the Implementation of the Hyogo Framework for Action. UNISDR UNSotISfDR, Geneva, Switzerland.

URAMA KC and OZOR N (2010) Impacts of climate change on water resources in Africa: The role of Adaptation. African Technology Policy Studies Network (ATPS) 29. URL: www.ourplanet.com/ climate-adaptation/UramaOzorv.pdf (Accessed 22 August 2017.

VERDIN J, FUNK C, SENAY G and CHOULARTON R (2005) Climate science and famine early warning. Phil. Trans. R. Soc. Lond. B: Biol. Sci. 360 (1463) 2155-2168. https://doi.org/10.1098/rstb.2005.1754

VÖRÖSMARTY CJ, DOUGLAS EM, GREEN PA and REVENGA C (2005) Geospatial indicators of emerging water stress: an application to Africa. AMBIO 34 (3) 230-236. https://doi. org/10.1579/0044-7447-34.3.230

WANG W, ERTSEN MW, SVOBODA MD and HAFEEZ M (2016) Propagation of drought: from meteorological drought to agricultural and hydrological drought. Adv. Meteorol. 2016 Article ID 6547209, 5 pp.

WILHITE DA and GLANTZ MH (1985) Understanding: the drought phenomenon: the role of definitions. Water Int. 10 (3) 111-120. https://doi.org/10.1080/02508068508686328

WILHITE DA and SVOBODA MD (2000) Drought Early Warning Systems in the Context of Drought Preparedness and Mitigation. World Meteorological Organization (WMO), Lisboa.

WILLMOTT CJ and FEDDEMA JJ (1992) A more rational climatic moisture index. The Professional Geogr. 44 (1) 84-88. https://doi. org/10.1111/j.0033-0124.1992.00084.x

WMO (2006) Drought monitoring and early warning: concepts, progress and future challenges, Geneva, Switzerland. .

WMO and GWP (2016) Handbook of Drought Indicators and Indices (Svoboda $M$ and Fuchs BA). Integrated Drought Management Programme (IDMP), Integrated Drought Management Tools and Guidelines Series 2, World Meteorological Organization (WMO) and Global Water Partnership (GWP), Geneva, Switzerland. 